\title{
Comparison of Fluoride I ontophoresis and Dentin Bonding Agent Application in the Treatment of Dentin Hypersensitivity: A clinical study
}

Rohan Sethi ${ }^{1}$, Maya Sanjeev Indurkar ${ }^{2}$

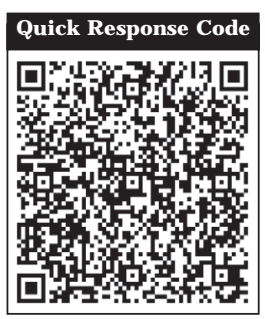

doi: $10.5866 / 2015.7 .10013$

1Post Graduate Student

2Professor \& H.O.D

Department of Periodontology,

Government Dental College and Hospital, Aurangabad,

Maharashtra-431001, India

\section{Article Info:}

Received: J anuary 8, 2015

Review Completed: February 7, 2015

Accepted: March 11, 2015

Available Online: April, 2015 (www.nacd.in)

(c) NAD, 2015 - All rights reserved

\section{Email for correspondence:}

rohansethi8@gmail.com

\begin{abstract}
:
Background: Dentin hypersensitivity $(\mathrm{DH})$ is a recurrent condition causing discomfort and most of the time, pain to the patient, generally occurring post scaling and root planing which also deters them from maintaining adequate oral hygiene. Various measures are used for treatment of this condition in clinic or in home care.
\end{abstract}

Materials and Method: The subjects recruited in this randomized clinical study gave a history of tooth hypersensitivity and post scaling sensitivity of the teeth. The patients were subjected to a tactile test, air blow for 1 second and cold water stimuli and their responses were recorded on a verbal discomfort scale. A total of 28 sites (28 teeth) were divided into Group A (1.23\% APF gel iontophoresis (FI) $n=14)$; and Group B (light cured Dentin bonding agent $(D B A) n=14$ ). The teeth were evaluated immediately after half an hour of the treatment and at the end of 2 weeks. In case of persistent complaint, the tooth was retreated with the same modality.

Results: The results were statistically analyzed using Wilcoxon matched pairs test and Mann Whitney $U$ tests. DBA had a better effect over 2 week's period while FI had better immediate results. More recurrence was seen with $\mathrm{FI}$.

Conclusion: Both the techniques are useful methods of treatment of $\mathrm{DH}$. In this study DBA gave better results than FI.

Key words: Dentin hypersensitivity; fluoride; iontophoresis; dentin bonding agent; APF gel

\section{INTRODUCTION}

Dentine hypersensitivity is one of the most common complaints with which patients report to a dental clinician. Besides causing discomfort, the condition may deter a person from establishing or maintaining adequate oral hygiene procedures, further complicating oral health. Thus a dissatisfactory plaque control may lead to compromised periodontal health. According to Addy et al dentine hypersensitivity $(\mathrm{DH})$ is characterized by 'pain derived from exposed dentine in response to thermal, chemical, tactile or osmotic stimuli which cannot be explained as arising from any other dental defect or pathology.. ${ }^{1}$ A recent modication to this denition has been made to replace the term 'pathology' with the word 'disease'.'

Generally, the incidence of hypersensitivity in most populations' ranges between $10-30$ per cent of 
the general population. ${ }^{3}$ The main cause of dentinal hypersensitivity is exposed dentinal tubules. Various etiological factors are loss of enamel, denudation of cementum, attrition, abrasion, abfraction, erosion (intrinsic and extrinsic),gingival recession, tooth mal position, thinning, fenestration, absent buccal alveolar bone plate, periodontal disease and its treatment, periodontal surgery, patient habits (smoking, tobacco chewing, etc). ${ }^{4}$

Although several hypotheses have been advanced to explain how external stimuli may influence the nerve bers, the most widely accepted is the hydrodynamic theory, where movement of the fluid within dentin transduces surface stimuli by deformation of pulpal mechanoreceptors which, in turn, causes pain and hypersensitivity. ${ }^{5}$

Various modes of treatment in both the home and the dental office have been tried with varied success. The home measures include the use of desensitizing dentifrices or mouthwashes with active compounds such as sodium uoride ( $\mathrm{NaF})$, potassium nitrate, strontium chloride, stannous uoride, etc. ${ }^{6-9}$ The ofce measures include the use of cavity varnishes, anti-inammatory agents, uoride compounds, calcium compounds, restorative resins, etc. ${ }^{10-14}$ These different modal ities have shown varied results over time. The main aim of this clinical study was to compare the efficacy of iontophoresis using acidulated phosphate gel (APF) gel and dentinbonding agent (DBA) in providing relief from hypersensitivity and post scaling hypersensitivity.

\section{Materials and Methods}

Patients with a history of tooth hypersensitivity were selected from the Department of Periodontics, Government Dental College and Hospital, Aurangabad, Maharashtra, irrespective of gender, or socioeconomic status. The teeth which were identied by the patient as hypersensitive and veried by the light stroke of a dental explorer along the cervical area of all teeth present were selected. Subjects fullling the inclusion and exclusion criteria were enrolled in the study. The study was accepted by the institutional review board of Government Dental College and Hospital, Aurangabad, and all participants signed informed consent forms.

Inclusion criteria were: History of tooth hypersensitivity to any stimuli; Hypersensitivity after scaling and root planing; Good physical health; Willingness to participate in the study.
Exclusion criteria were: defective restorations, cracked tooth syndrome, fractured undisplaced cusps, chipped teeth, deep periodontal pockets, or a tender tooth in the same quadrant as the hypersensitive teeth; orthodontic appliances, dentures, or bridgework that would interfere with the evaluation of hypersensitivity; taking antibiotics and/or anti-inammatory drugs; already undergoing treatment for tooth hypersensitivity; deep dental caries or large restorations showing pul pal response; pregnant or lactating females; periodontal surgery within the previous 6 months; chronic systemic disease; or an unshielded pacemaker.

The patients who qualified, enrolled from J anuary 2014 to February 2014, were evaluated using the threestimuli. The teeth were isolated with rolls of cotton and the stimuli were applied. For all stimuli tests, patient response was recorded on the following scale: $0=$ no signicant discomfort, or awareness of stimulus; 1 =discomfort, but no severe pain; 2 =severe pain during application of stimulus; and $3=$ severe pain during and after application of stimulus. ${ }^{6}$

Following stimuli tests were applied to evaluate the response of sites at baseline, after half an hour (immediate response) and after two weeks - 1) Tactile test: A sharp dental explorer (17/23) was passed lightly across the affected area of the tooth, at a right angle to the long axis of the tooth. After three repetitions a score, using the discomfort scale, was noted. 2) Air blast test: A blast of air from a dental syringe at 60 pound/inch ${ }^{2}$ pressure was directed onto the affected area of the tooth for 1 second from a distance of $10 \mathrm{~mm}$ (measured by taping scale to the three-way syringe); the adjacent teeth were protected using cotton rolls. 3) Cold water test: A pre-cooled $1 \mathrm{cc}$ disposable syringe was Iled with freshly melted ice-cold water. After isolating the specic tooth, $0.2 \mathrm{ml}$ of the water was slowly expelled from the syringe onto the tooth surface (Figure 1).

Throughout the study, the stimuli tests were applied in the same order, with a minimum 10minute gap between the application of different stimuli. After the tests were performed, the teeth rated 2 or more for any of the two tests were sel ected for thestudy. A total of 28 teeth sites from 4 patients included in this study were randomly divided into two groups: group A: 14 teeth treated with 1.23\% Acidulated Phosphate Fluoride gel applied using an iontophoresis delivery system (FI); group B: 14 teeth 
treated with HEMA-G desensitizer, applied according to manufacturer's instructions. All patients underwent scaling and polishing before the study and were instructed not to use any other desensitizing agent during the study.

Group A: I ontophoresis-the tooth was isolated with rolls of cotton, dried, and APF gel was applied with an applicator tip. The metallic tip of iontophoresis unit (Figure 2) was pressed against the tooth surface and the circuit was completed. The current applied to the tooth was progressively increased until the patient complained of pain or sensitivity. Upon reaching the threshold, the APF gel was applied again and the procedure was repeated at a lower ampere current (Desensitron ${ }^{\circledR}$ , Parkell Inc., Edgewood, NY, USA) using APF gel, $1.23 \% \mathrm{w} / \mathrm{w}+$ phosphoric acid, $0.3 \%$.

Group B: Dentin bonding agent (Gluma ${ }^{\circledR}$ 2B ond, Heraeus Kulzer, Hanau, Germany) (Figure 3). The teeth to be treated were isolated with cotton rolls, cleaned, and dried with cotton pledgets. A drop of desensitizer was then applied using a cotton applicator and left for 30 seconds. The surface was then carefully dried with a stream of air until the fluid film had disappeared and the surface was no longer shiny. The patient then rinsed thoroughly with water.

The teeth were evaluated at baseline, immediately after treatment at day 0 , at 2 weeks. If there was a failure at the 2-week interval, the affected tooth was treated again with the same solution as before and evaluated again. Failure was dened as the recurrence of hypersensitivity at a score of 2 or higher for any two of the three stimuli tests.

\section{Statistical Analysis:}

Data were analyzed on an intention-to-treat basis with the tooth site as the unit of statistical analysis. The reduction in the discomfort scalescores from baseline was considered as the primary outcome variable. The Wilcoxon matched pairs test and Mann Whitney $U$ test were used for the statistical analysis.

\section{Results:}

The cross tabulation method was used to observe the total number of sites with score $0,1,2$ or 3 on discomfort scale at immediate (Table 1) and post 2 weeks (Table 2 ) for both the treatment modalities as per different stimuli tests. A score of $<2$ is regarded as successful treatment. The total number of sites showing a score $<2$, immediately after treatment with $\mathrm{FI}$ were more as compared to DBA group for tactile and cold water test. But after 2 weeks more teeth sites showed a score of $<2$ in DBA group for tactile and cold water tests as compared to FI treated sites.

The Man Whitney U test was applied to compare the two treatment modalities for the three different sensitivity tests. The difference between the two treatment groups was statistically significant at 2 weeks for col d water test, with lower discomfort scale values achieved with DBA (Table 3).

Table 1: Immediate results of both the treatment modalities for all the stimuli test

\begin{tabular}{|c|c|c|c|c|c|c|}
\hline \multirow[t]{2}{*}{ Method } & & \multicolumn{4}{|c|}{$\begin{array}{c}\text { Immediate } \\
\text { Grade }\end{array}$} & \multirow[t]{2}{*}{ Tota } \\
\hline & & 0 & 1 & 2 & 3 & \\
\hline \multirow[t]{3}{*}{ Tactile } & iontophoresis & 4 & 7 & 3 & 0 & 14 \\
\hline & $\overline{\mathrm{DBA}}$ & 2 & 7 & 5 & 0 & 14 \\
\hline & Total & 6 & 14 & 8 & 0 & 28 \\
\hline \multirow[t]{3}{*}{ Air blow } & iontophoresis & 0 & 3 & 7 & 4 & 14 \\
\hline & DBA & 1 & 7 & 6 & 0 & 14 \\
\hline & Total & 1 & 10 & 13 & 4 & 28 \\
\hline \multirow[t]{3}{*}{ Cold Water } & iontophoresis & 5 & 8 & 1 & 0 & 14 \\
\hline & DBA & 3 & 8 & 2 & 1 & 14 \\
\hline & Total & 8 & 16 & 3 & 1 & 28 \\
\hline \multirow[t]{3}{*}{ Total } & iontophoresis & 9 & 18 & 11 & 4 & 42 \\
\hline & DBA & 6 & 22 & 13 & 1 & 42 \\
\hline & Total & 15 & 40 & 24 & 5 & 84 \\
\hline
\end{tabular}

Table 2 Post 2 weeks results of both the treatment modalities for all the stimuli test.

\begin{tabular}{|c|c|c|c|c|c|c|}
\hline \multirow[t]{2}{*}{ Method } & & \multicolumn{4}{|c|}{$\begin{array}{c}\text { 2nd Week } \\
\text { Grade }\end{array}$} & \multirow[t]{2}{*}{ Tota } \\
\hline & & 0 & 1 & 2 & 3 & \\
\hline \multirow[t]{3}{*}{ Tactile } & iontophoresis & 3 & 7 & 4 & 0 & 14 \\
\hline & $\mathrm{DBA}$ & 7 & 6 & 1 & 0 & 14 \\
\hline & Total & 10 & 13 & 5 & 0 & 28 \\
\hline \multirow[t]{3}{*}{ Air blow } & iontophoresis & 1 & 9 & 4 & 0 & 14 \\
\hline & $\mathrm{DBA}$ & 7 & 1 & 3 & 3 & 14 \\
\hline & Total & 8 & 10 & 7 & 3 & 28 \\
\hline \multirow[t]{3}{*}{ Cold Water } & iontophoresis & 2 & 7 & 5 & 0 & 14 \\
\hline & $\mathrm{DBA}$ & 7 & 7 & 0 & 0 & 14 \\
\hline & Total & 9 & 14 & 5 & 0 & 28 \\
\hline \multirow[t]{3}{*}{ Total } & iontophoresis & 6 & 23 & 13 & 0 & 42 \\
\hline & $\mathrm{DBA}$ & 21 & 14 & 4 & 3 & 42 \\
\hline & Total & 27 & 37 & 17 & 3 & 84 \\
\hline
\end{tabular}


Table 3 Mann-Whitney $U$ test used to compare DBA and FI for the three different stimuli tests

\begin{tabular}{|c|c|c|c|c|}
\hline \multirow{2}{*}{\multicolumn{2}{|c|}{$\begin{array}{l}\text { Test } \\
\text { applied }\end{array}$}} & \multicolumn{2}{|c|}{ Median Grade } & \multirow[t]{2}{*}{ P-value } \\
\hline & & iontophoresis & DBA & \\
\hline \multirow[t]{4}{*}{ Tactile } & Baseline & 2 & 2 & 0.982 \\
\hline & Immediate & 1 & 1 & 0.352 \\
\hline & At 2 weeks & 1 & 0.5 & 0.094 \\
\hline & & iontophoresis & DBA & \\
\hline \multirow{4}{*}{$\begin{array}{l}\text { Air } \\
\text { blow }\end{array}$} & Baseline & 3 & 3 & 0.999 \\
\hline & Immediate & 2 & 1 & $0.024^{*}$ \\
\hline & At 2 weeks & 1 & 0.5 & 0.635 \\
\hline & & iontophoresis & DBA & \\
\hline \multirow{3}{*}{$\begin{array}{l}\text { Cold } \\
\text { water }\end{array}$} & Baseline & 3 & 3 & 0.541 \\
\hline & Immediate & 1 & 1 & 0.306 \\
\hline & At 2 weeks & 1 & 0.05 & $0.014 *$ \\
\hline
\end{tabular}

*significant results $(\mathrm{P}<0.005)$

Wilcoxon matched paired t tests was applied to compare basel ine values with immediate and post 2 weeks score for both treatment groups. For tactile, air and cold blow test, the discomfort values for baseline versus immediate and baseline versus 2 weeks post treatment groups was highly statistically significant for both the groups. The reduction in discomfort score for tactile and cold water test at 2 weeks for DBA group is more as compared to the FI group (F igure 4). There were a larger number of patients who required a repeat application of APF gel with iontophoresis (9/14) as compared with the DBA group (2/14) post 2 weeks.

\section{Discussion:}

In the present study the comparison of the two treatment modalities to treat dentinal hypersensitivity has been briefly studied in vivo. I ontophoresis with fluoride application is a time tested treatment option for hypersensitivity. DBA is an upcoming modal ity which has scope for innovation and improvement. DBA appears to have an obvious disadvantage of weaker retention than iontophoresis pushed fluorideions. Thenewer generations of DBA have shown promise in reducing hypersensitivity due to better adhesion to the dentinal surface.

In the present study, both the agents, that is, $\mathrm{FI}$ and DBA provided immediate and post 2 weeks relief from tooth hypersensitivity. DBA was found to give better results post 2 weeks while iontophoresis had better immediate result. The immediate relief by iontophoresis can be attributed to deeper penetration of fluoride ions while the DBA requires time to clog the dentinal tubules and prevent irritants to penetrate. This impervious layer

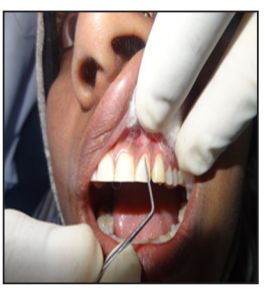

Tactile test

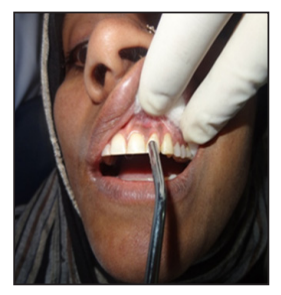

Air blow test

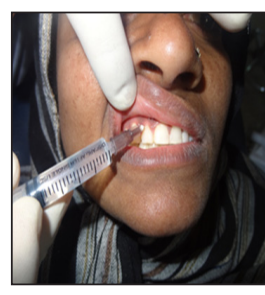

Cold water test

Figure 1: Various stimuli tests used.

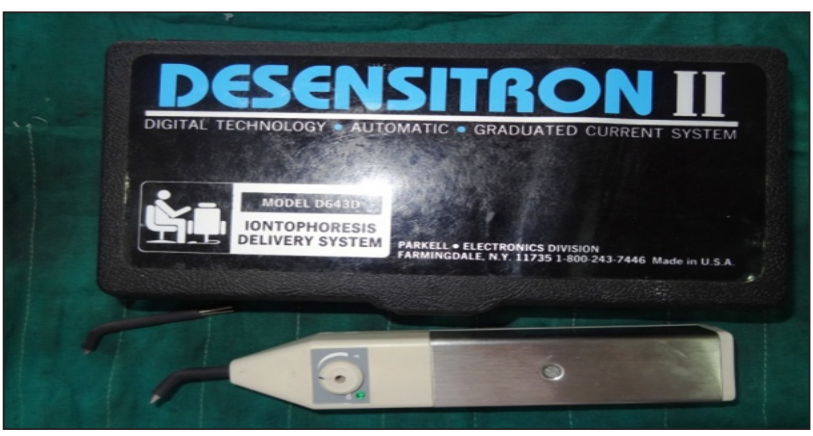

Figure 2: I ontophoresis unit

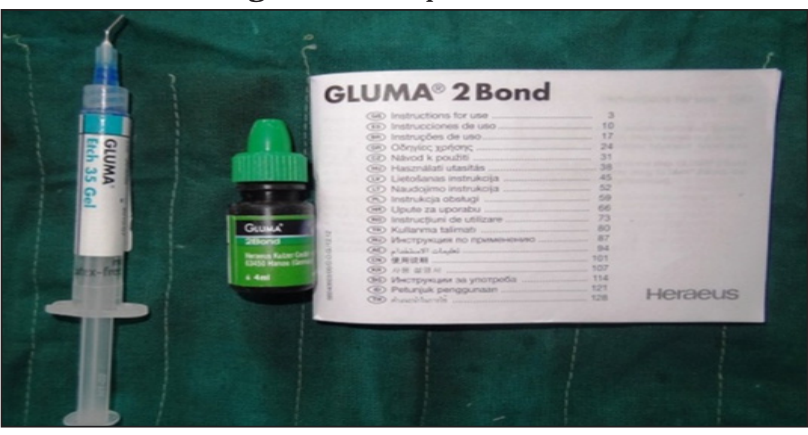

Figure 3: Dentin bonding agent - Gluma 2Bond

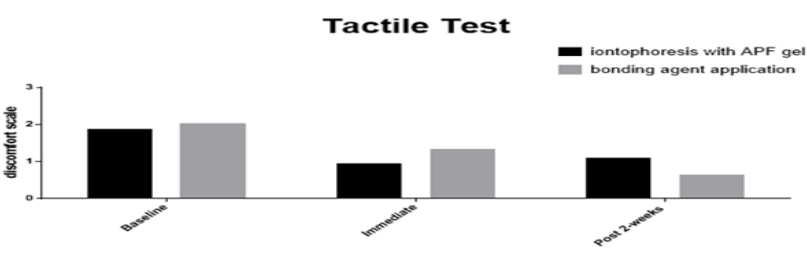

Air Blow Test

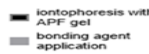
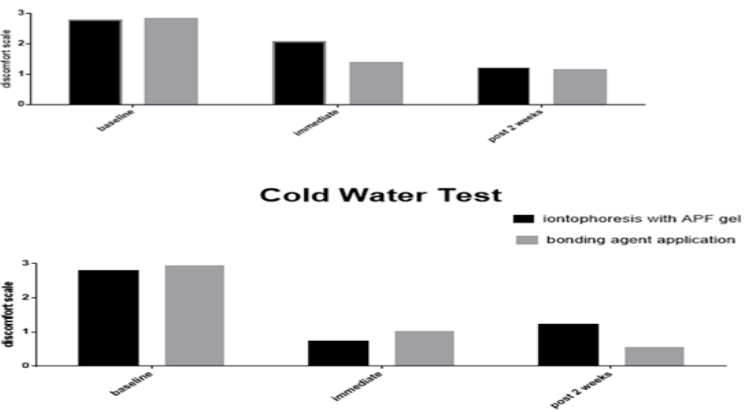

Figure 4-Graphical presentation of comparison of FI and DBA at baseline, immediate and two weeks for all three stimuli tests. 
thus formed stays longer than effect of APF gel with iontophoresis. There were a larger number of patients who required a repeat application of APF gel with iontophoresis (9/14) as compared with the DBA group (2/14) post 2 weeks indicating a longer period of action of the DBA. In the present study we have used the three subjective tests for evaluating the hypersensitivity - tactile test, air blow test and cold water test. These have been used in several previous trials of hypersensitivity treatment modalities. ${ }^{15}, 16$ We found a correlation of results achieved with the tactile and cold water test for both the treatment modalities.

In a similar study by Aparna et al 2010, the $1.23 \%$ APF gel with iontophoresis was found to be superior over DBA after 2 weeks. ${ }^{15}$ In study by Singal et al, 2005; NaF iontophoresis was compared to DBA, both agents showed signicant reduction in sensitivity at all time interval s compared to baseline; however, $\mathrm{NaF}$ had a comparatively greater effect than HEMA-G at both the 1- and 3-month intervals; an almost equal number of teeth in both groups required repeat doses. ${ }^{16}$

So far the exact mechanism of action of the iontophoresis is not known. Several hypotheses were proposed - formation of reparative dentin in response to the el ectric stimuli, paresthesia of the intra pulpal nerve endings and microprecipitation of calcium fluoride in the dentinal tubules as the negative charge of electric current pushes the negatively charged fluoride ions deeper in the tubules. ${ }^{17}$

Some of the shortcomings of the study were small sample size and subjective nature of discomfort scale used. Also there is need to find better and precise diagnostic tests and effective treatment options in the field of dentinal hypersensitivity for which more scientific research is necessary.

\section{Conclusion:}

Dentin hypersensitivity is an enigma to dentists and other oral health professionals as a particular treatment modality cannot be called as a cure for this apathy. In this study the DBA has proven to be better as compared to $1.23 \%$ APF gel fluoride iontophoresis after 2 weeks, with a less number of recurrence cases with DBA over 2 weeks. DBA is a simple 2 step procedure and is painless. It is a cheaper option too. FI offers an in office treatment which supplemented by a desensitizing tooth paste can provide relief to the post scaling sensitivity patients also.
Acknowledgements: We would like to acknowledge Mr Shree Vallabh Sane for his valuable contributions in the statistical analysis related to the study.

Conflict of interest: No external funding, apart from the support of the author's institution, was available for this study. The authors declare that there are no conflicts of interest in this study.

\section{References:}

1. Addy M, Mostafa P, Absi EG, Adams D. Cervical dentine hypersensitivity. Etiology and management with particular reference to dentifrices. In: Rowe $\mathrm{NH}$, ed. Proceedings of Symposium on Hypersensitive Dentin. Origin and Management. University of Michigan, Ann Arbor, MI, 1985: 147-167.

2. Canadian Advisory Board on Dentin Hypersensitivity. Consensus-based recommendations for the diagnosis and management of dentin hypersensitivity. J Can Dent Assoc 2003; 69:221-226.

3. Rees J S, Addy M. A cross- sectional study of dentine hypersensitivity. J Clinical Periodontol 2002; 29:997-1003.

4. Chabanski MB, Gillam DG. Aetiology, prevalence and clinical features of cervical dentine sensitivity: a review. J Oral Rehab 1997; 24:15-19.

5. Brannstrom M, Astrom A. The hydrodynamics of the dentine; I ts possible relationship to dentinal pain. Int Dent J 1992; 22:219-227.

6. Tarbet WJ , Silverman G, Stolman J M. An evaluation of two methods for the quantitation of dentinal hypersensitivity. J Am Dent Assoc 1979; 98:914-918.

7. Tarbet WJ, Silverman G, Fratarcangelo PA, Kanapka J A. Home treatment for dentinal hypersensitivity: A comparative study. J Am Dent Assoc 1982; 105:227-230.

8. Wey SHY, Lainson PA, Henderson W, Wolfson SH. Evaluation of dentifrices for the relief of hypersensitive tooth surfaces. Quintessence Int 1980; 1:67-73.

9. Blong MA, Volding B, Trash WJ , J ones DL. Effects of a gel containing $0.4 \%$ stannous uoride on dentinal hypersensitivity. Dent Hyg 1985; 59:489-492.

10. Wycoff SJ . Current treatment for dentinal hypersensitivity. Compend Contin Educ Dent 1982;3:113-115.

11. Ong G. Desensitizing agents: A review. Clin Prev Dent 1986; 8:14-18.

12. Laufer B, Mayer J , Gedalia I. X-ray diffraction and scanning electron microscope investigations of fluoride treated dentin in man. Arch Oral Biol 1976; 21:285-290.

13. Pashley DH. Dental permeability, dentinal sensitivity and treatment through tubule occlusion. J Endod 1986; 12:465474.

14. J avid B, Barkhordar RA, Bhinda SV. Cyanoacrylate- a new treatment for hypersensitive dentin and cementum. J Am Dent Assoc 1987; 114:486-488.

15. Aparna S, Swati Setty, Srinath Thakur. Comparative efficacy of two treatment modalities for dentinal hypersensitivity: A clinical trial. Indian J Dent Res 2010; 21(4):544-548.

16. Singal P, Gupta R, Pandit N. 2\% Sodium FluorideI ontophoresis Compared to a Commercially Available Desensitizing Agent. J Periodontol 2005; 76:351-357.

17. Gangarosa LP, Park NH. Practical considerations in iontophoresis of fluoride for desensitizing dentin. J Prosthet Dent 1978; 39:173-178. 